\title{
The potential of student narratives to enhance quality in higher education
}

\section{Claire Hamshire}

Department of Health Professions, Manchester Metropolitan University, Bonsall Street, Manchester, United Kingdom, M15 6GX c.hamshire@mmu.ac.uk

Rachel Forsyth

Centre for Excellence in Learning and Teaching, Manchester Metropolitan University, Manchester, United Kingdom M15 6BH r.m.forsyth@mmu.ac.uk

\section{Amani Bell}

Education Portfolio, Room 254, Level 2 South Fisher Library, The University of Sydney, NSW University of Sydney, Australia amani.bell@sydney.edu.au

\section{Matthew Benton}

Education Portfolio, Room 254, Level 2 South Fisher Library, The University of Sydney, University of Sydney, Australia, mben4237@uni.sydney.edu.au

\section{Roisin Kelly-Laubscher}

Science Academic Development Programme, 3.06.1 (HW Pearson Building) University of Cape Town, Private Bag, Rondebosch, 7701, South Africa, roisin.kelly@uct.ac.za

\section{Moragh Paxton}

Language Development Group, Centre for Higher Education Development, University of Cape Town, Private Bag, Rondebosch, 7701, South Africa, Moragh.Paxton@uct.ac.za

\section{'Ema Wolfgramm-Foliaki}

Centre for Learning \& Research in Higher Education (CLeaR), Centre for Learning and Research in Higher Education (CLeaR), The University of Auckland, Private Bag 92019, Auckland 1142, New Zealand, ea.wolfgramm@auckland.ac.nz 


\begin{abstract}
University policies are increasingly developed with reference to students' learning experiences, with a focus on the concept of the 'student voice'. Yet the 'student voice' is difficult to define, and emphasis is often placed on numerical performance indicators. A diverse student population has wide-ranging educational experiences, which may not be easily captured within the broad categories provided by traditional survey tools, which can drown out the rich, varied and gradual processes of individual development. There is no single tool which can be used to measure students' experiences. This paper draws on findings from four narrative inquiry studies, carried out in the United Kingdom, Australia, South Africa and New Zealand, to illustrate how a narrative approach could be used to complement performance indicators. This provides a richer context for educators' understanding of students' experiences and for supporting and setting institutional agendas.
\end{abstract}

Keywords: student satisfaction, narrative inquiry, student voice, evaluation, higher education 


\section{Performance indicators and the student experience}

Performance indicators have become a key part of the quality processes in higher education institutions. These may be in the form of statistics from surveys, participation rates, progression data, student engagement figures, or graduate employment rates (Buckley 2012). They are used internationally for institutional benchmarking, quality enhancement, government funding decisions and in some case to design strategies to widen participation and increase the success of students from diverse backgrounds (Coates 2010, Hazelkorn 2007).

There are concerns that a focus on performance indicators is partly because of their perceived value in marketing institutions (Law 2010), which may encourage a more consumerist approach by students (Molesworth, et al. 2009). A more positive perspective is that information about the student experience including participation rates, progression data, and student engagement figures is needed to make quality enhancements, so that universities are able to react to perceived problems and ensure that students are in a position to make the most of their courses (Buckley 2012, Council on Higher Education 2016).

Although performance indicators are carefully analysed and used to set policy and procedures, little of the individual, emotional and temporally dependent experience of being a student is evident. Students' individual voices about their experiences in higher education can become lost, limiting overall understanding of the expectations and experiences of a diverse student population. An over-reliance on reductionist measures of quality can lead to the exclusion of equally credible ways of considering the student experience of higher education, and without this, 'of the individual student with his or her own challenges and struggles, we gain little sense' (Barnett 2007, p. 8)

The literature suggests that students' learning experiences are influenced by a wide range of factors, including adaptation to the higher education environment, personal issues, cultural differences, financial problems and linguistic and academic difficulties (Benseman, et al. 2006, Bishop 2003, Chu, et al. 2013, Devlin, et al. 2012, Hamshire, et al. 2012, Kapp, et al. 2011, Tinto, et al. 1993). Studying at higher education involves an adjustment in lifestyle for all students and stabilisation in individual and family circumstances is necessary to ease the process of becoming a student (Case, et al. 2010, Palmer, et al. 2009). This learning transition can be understood as part of the continuous process of identity construction and involves both a personal and social transformation (Britton, et al. 1999). Ultimately higher education is necessarily a process of becoming (Barnett 1994) and can therefore be considered as a transformation of 'being' (Barnett 2007). If aggregated performance indicators are used without additional information from qualitative data, it is possible to assume causality and imply linkages that are difficult to justify. This may lead to a somewhat narrow interpretation of students' experiences.

Student success, satisfaction and on-going engagement are complex phenomena, related to factors such as the educational and social experiences of the student prior to enrolling; the social and academic engagement between the student and the institution; and the commitment of the student to the institution (Urwin, et al. 2010). In addition, as explored by Solomonides et al (2012), engagement and satisfaction are not static phenomena but vary over time in response to both academic and outside influences. It is, therefore, difficult to capture the complexity of individual stories 
when students are sampled at single points in time and only a 'temporal slice' of their experiences is considered.

Using findings from four narrative studies in the United Kingdom (UK), Australia, South Africa and New Zealand, this paper offers insights into individual learning experiences and illustrates how a narrative approach may be used to complement performance indicators to support quality enhancement.

\section{Limitations of performance indicators in quality enhancement}

The principal performance indicators that relate to students' experiences are based on progression data, participation rates and student surveys. Standardised national student questionnaires are used in countries such as the United Kingdom, Australia, South Africa and the USA. Progression and participation rates are often also collected, published and compared nationally, for example in South Africa (Council on Higher Education 2016) and the UK (Higher Education Statistics Agency (HESA) 2016), and internationally(The World Bank 2016).

The data may form the basis for institutional key performance indicators or even be used as proxies for teaching quality on individual courses (Buckley 2012). In the UK, Ramsden et al. (Ramsden, et al. 2010) found that institutional managers strongly valued the National Student Survey (NSS) as a way to identify and remedy problems with the student experience, even though Brennan and Williams (Brennan, et al. 2004) highlighted that reliance on any single method of collecting student feedback has its drawbacks..

The publication of quantitative data from surveys may lead to a clear focus on the setting of numerical targets, such as being above sector average, avoiding low scores, increasing response rates and ensuring that the institution achieves the best possible rating when the satisfaction snapshot is taken. As Gibbs (2012, p. 9) points out, 'Regardless of the validity of currently available data, institutional behaviour is being driven by data to an unprecedented extent'.

In South Africa the use of national student surveys is relatively new, with the South African Survey of Student Engagement (South African Survey of Student Engagement (SASSE) 2012) first being piloted in 2009. Until recently, quality enhancement in South Africa relied on information from participation rates, progression data and national benchmark tests. Participation rates and progression data provide figures on the number of students entering higher education and their performance over time. These data also provide insights into access and performance based on race, which is extremely important in the South African context, given the country's history of educational inequality that is a legacy of the apartheid régime. Despite these benefits, such quantitative data remain limited in that they do not provide explanations of these figures. Furthermore, generalisation of this information based on race can neglect the fact that the experience of students from a particular race is not homogenous (Nomdo 2006). In the New Zealand context, participation rates and progression data are also used as indicators of student engagement and performance.

There is a long history of national student surveys in Australia, with the annual Australian Graduate Survey (AGS) (GraduateCareers Australia 2016), commencing in 1972. The AGS seeks to determine information about recent graduates, such as their 
employment status and their views on their higher education experience, and also collects data about graduates' perceptions of their higher education experience. Surveys of current students include the Student Experience Survey (SES), which is a national survey used by the Australian Government to monitor quality and to provide information to prospective students via a national website.

However valuable the data may be for the quality assurance agenda, the types of questions included in student surveys can limit their value for quality enhancement. Questionnaires using closed answers cannot adequately describe the variety of student experiences and there is evidence to show that students have disparate understandings of survey items (Bennett, et al. 2014). Questions about student satisfaction may therefore receive different answers at different stages of an individual's journey through their higher education studies: at times, learning in higher education may be challenging and uncomfortable for students as they develop as autonomous learners and team workers, and their discomfort may be expressed as dissatisfaction.

\section{The case for narratives}

To gain an authentic understanding of students' experiences, performance indicators can be supplemented with opportunities for students to describe and construct their multidimensional experiences as they change and shape over time. Narrative research is one approach that can be used for this purpose.

Narratives have been used as a means of communicating experience for centuries (Koch 1998). Narrative research is concerned with the construction, interpretation and depiction of storied accounts of lived experiences and aims to organise a sequence of lived events into a whole (Elliott 2007). It is a methodology that is set in stories of individual experiences (Webster, et al. 2007).

As such, narratives are a means of human sense-making as they provide an opportunity to view and discuss experiences as sequential and meaningful, displaying transformation or change (Squire 2008). Narrative methods are typically used in research to address 'real-life' issues as they always reflect an individual's perspective and they result in 'unique and rich' data (Lieblich, et al. 1998). Researchers who use narratives do so to see different layers of meaning and understand more about social and individual change over time (Andrew, et al. 2009).

Within all such narratives there is temporality (a sequence of actions over time) and the consideration of this 'sequences of action' within stories separates narrative analysis from other types of analysis (Riessman 2008). The analysis of narratives becomes a way of analysing individual lived experiences to discover narrative linkages (Gubrium, et al. 2009). This approach is therefore well suited to address the complexities of students' experiences, providing opportunities for students to tell their own nuanced and complex stories and describe how everyday academic, personal and social circumstances can influence their experiences. Listening to, and subsequently analysing, the stories that students tell from their own perspective can give insight into their experiences, enhance understanding and thus improve provision for future students. 


\section{Students' stories}

To illustrate the potential of student stories to contextualise quantitative data on the student experience, examples are presented here from studies in four countries where performance indicators are becoming key drivers in quality enhancement: the UK, Australia, South Africa and New Zealand. All studies received ethics approval from their institutions. Pseudonyms are used throughout the findings section and any identifying features (such as, name of residential college) have been removed.

\section{United Kingdom}

A three-year longitudinal study with physiotherapy students was undertaken to investigate their undergraduate learning experiences (Hamshire, et al. 2014). Seven students were interviewed on at least five occasions across the three years of their studies. At each interview they were encouraged with a narrative prompt to tell the stories of their experiences as a series of 'episodes' beginning and finishing wherever and however they felt was most appropriate. This allowed the students to describe their own journeys in their own words, without imposing a particular time-frame or targeting a particular aspect of experience; to present a temporal, multidimensional view of student experiences.

At each subsequent interview the students were asked to tell the next 'episode'. Each of the interviews lasted 40-50 minutes, and they were audio-recorded and subsequently transcribed verbatim.

Each of the students gave extended accounts of their learning experiences and both academic and personal factors could be seen to impact upon them, extracts from two of these narratives are presented here.

Jack described how he struggled to engage with the programme, and was initially surprised by the amount of work he had to do:

This course has moved so quickly. It was a lot of work, a lot of work and I definitely didn't do enough of it. The lectures I find difficult to concentrate in just because there's so many people. It can be difficult especially when you're getting a lecture at four o'clock.

Extracts from his narrative demonstrate how he became more reflective about the need to develop as an autonomous learner:

I completely forgot about the feedback after I came back. I suppose that would be useful, it might help me to plan what I need to do for this assignment coming up. I suppose it is just a matter of going through it with my personal tutor just to see where I am going wrong, where I need to improve and that sort of thing.

Although his results began to improve in the third year, he acknowledged that he still struggled to be motivated to start work on assessments and prepare for classbased sessions:

We're kind of expected to do even more this year of our own. I feel like we are expected to remember a lot of what we'd done last year 
so we had to do a lot of stuff on our own. I think the lecturers

expect more because you're in second year. I suppose in a way it's good doing self-learning and stuff but umm, I don't know, it might be nice to have a bit more of a helping hand.

The capture of narrative can also show how course design can impact on learner development. One of the mature students in the study, Maria, found her course difficult and at times was critical of her learning experiences:

I pushed myself so hard in the first year and I passed the first year so I didn't have to do any re-sits, which was good. I didn't pass with excellent grades but I think it was just about average with everyone else in class. It was hard; I must say it was hard. But it seems like the second year is already three times more intense than the first year! To be honest this first week and a half it has been so rushed, there is so much more information given each day and there is so much more to study in between; trying to fit in too much, too soon, too fast.

\section{Australia}

A similar study in Australia investigated the higher education experiences of Indigenous and non-Indigenous students. Four focus groups, were formed, totalling twenty-two students. At each of these focus groups the students were invited to tell their stories about their journeys to and through the university.

Each focus group was recorded and transcribed verbatim, and a thematic analysis conducted of the transcripts (Braun, et al. 2006), with a critical overlay of a postcolonial Indigenous lens conducted (Chilisa 2011). Two researchers analysed the transcripts independently and then discussed the findings in order to develop a shared understanding. In this paper, one student's experiences of higher education are presented, illustrating many of the themes that arose for other students in the study.

This narrative of one Indigenous first-generation third-year student is an illustrative example of the rich experiences contained in each student's journey. John begins by describing his first day on campus:

Coming from a school that had about 40 to 50 Indigenous students within the school, it was a massive change for me, a bit of a culture shock. Coming from a small country town into the big smoke was also a massive change. But everyone was quite receptive and there happened to be at least eleven country boys doing my degree, so it ended up being pretty good.

Commencing Indigenous students are provided with a week-long orientation programme of study skills and opportunities to befriend other Indigenous students. John found this support to be valuable:

The support systems, from the get-go, were second to none for me. Rather than me coming and having to find my feet, they found my feet for me. 
However, John's first year was not without its difficulties: So I took a gap year and forgot a lot of things. I did a lot of monotonous jobs and didn't really use my brain. So coming back to university for the first year, I kind of, I struck out pretty bad and didn't get the marks I wanted because I just lost that work ethic.

One thing that's really hindered me is just being away from home, being away from community and stuff. Like [there were] a fair few deaths in my first year, so that was pretty hard for me and not being able to take the time off. ... whereas if I was closer to home I would have been able to duck home.

John's parents did not complete high school, so their lack of understanding of the university system placed pressure on him:

Like, for instance, if I was to fail a mid-term or something they get a lot more worried for me than I am worried for myself. Because they don't understand the whole system of how you can come back from that - even though it might be worth $20 \%$, it's not like it's a $100 \%$. So I like to try to get Ds [distinctions] or HDs [high distinctions] in everything that I have control of.

Now that John is nearing the end of his degree, he can see the end goal in sight:

I've been able to snag an internship, so for me, that's what I'm doing this for. I live so far away, I've got four years of this, but now that there are job opportunities arising, it makes it a little bit more worth it. You can see your achievements unfold.

\section{South Africa}

The South African research involved 14 first-year undergraduate students; it used participatory learning and action methodologies (Bozalek, et al. 2010) and asked students to draw their experiences of their journeys at university. This methodology allowed students who were speakers of English as an additional language to express themselves more effectively. Students subsequently described their experiences to an interviewer using the drawing as a prompt. These interviews were video-recorded. Both social semiotic analysis and thematic analysis were used to analyse the student drawings and their descriptions of them.

The illustrations of two Xhosa-speaking female first-generation students show the complexity of the students' experiences.

\section{Figure 1: Zandi’s journey}




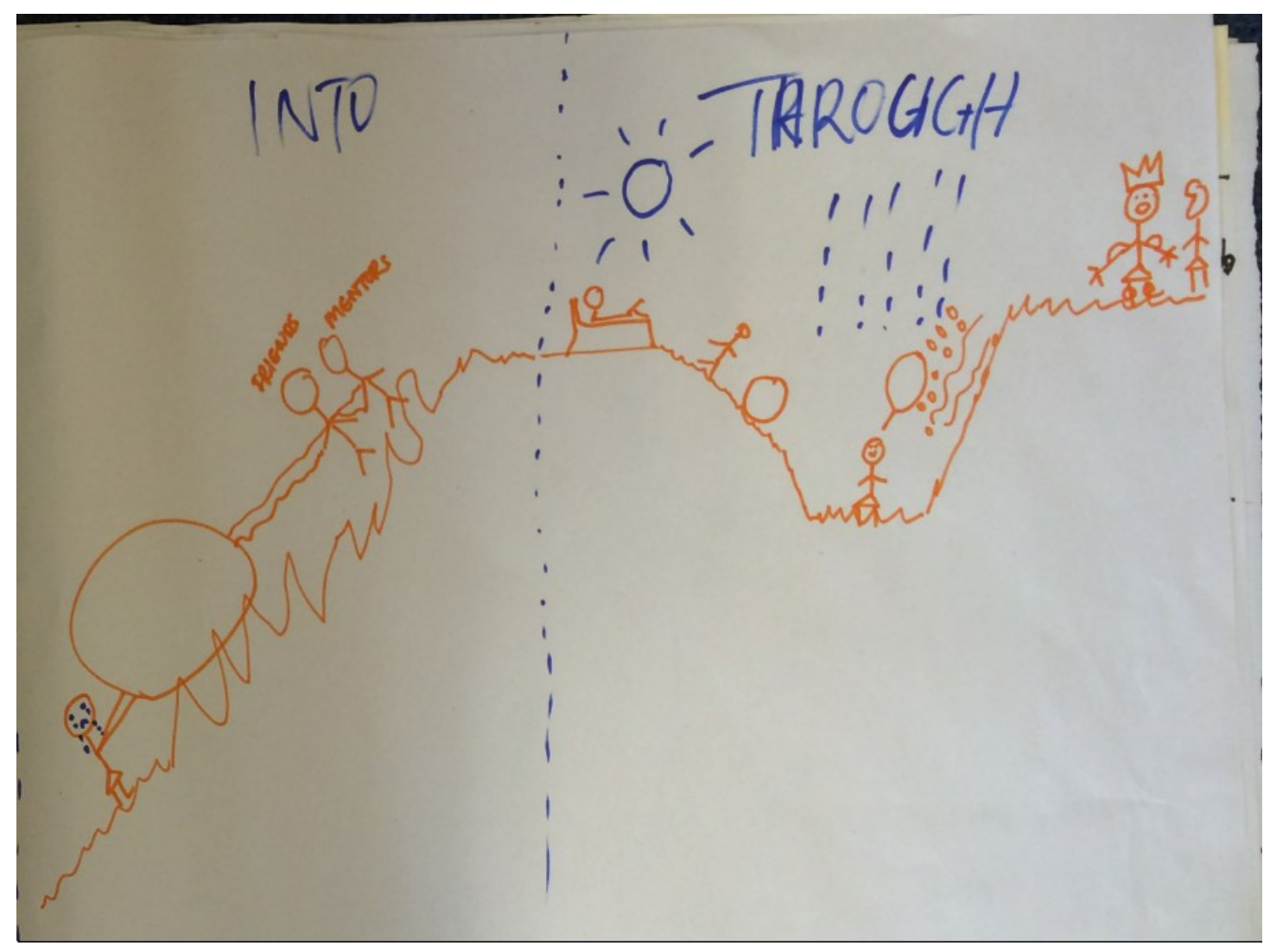

Zandi was studying medicine and it is clear from her drawing (Figure 1) that her narrative was not uniform. The start of her journey was not easy as indicated by the steep incline that formed a mountain in front of her. This represented her transition to university from home;

Having to leave home was really hard. I'm there pulling my own weight now, there's no friends, there's no family, there's no teachers and that for me was quite hard because I'm from [a rural area in South Africa] and then I'm coming here - Cape Town... I felt a little bit alone.

She talked about how the friends she eventually made in her residence and her mentors helped her through these difficult times and motivated her. Once she had settled into the university things got much easier as represented by the level surface, the sun shining above her and eventually a downhill slope;

That's me, going through university, just sitting there, chilling, having a good time because I got used to things. Everything was just fine; you can see the incline [points to downhill slope].

This downhill slope represents first semester after she had settled in. This 'easy' period was short-lived, however, and was soon followed by another steep incline and rain which represents second semester. The increased workload of the second semester made this student question her abilities and considered leaving the university. She thought;

Do I want to be a doctor, is this what I want to do...

Again her mentors helped her and tutored her through this. The road again flattened out and although she experienced a few bumps, life became easier again. Finally, 
when they went for their clinic and hospital visits her desire to be a doctor was strengthened. At this point she is wearing a crown in the picture, and she said,

I'm the boss now, I can do this thing, I am willing and I can do it.

\section{Figure 2: Ntombi's drawing of a two-sided face}

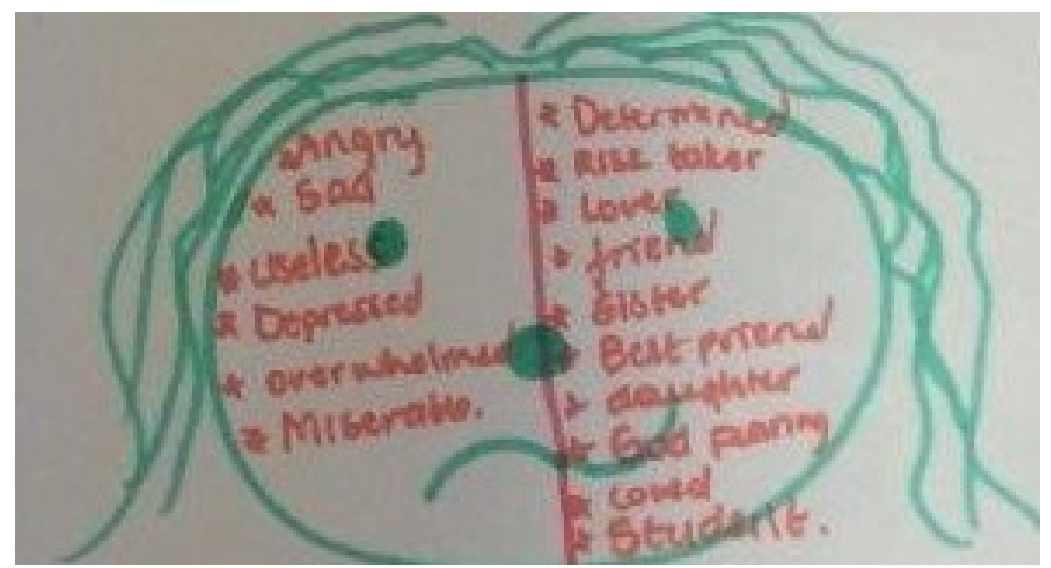

Ntombi's drawing (Figure 2) of her face with a happy and a sad side, indicates her ambivalence about whether or not she is good enough to be at university. This face is foregrounded, highlighting the importance of these thoughts. This ambivalence is supported by her spoken narrative;

Then I decided I was going to take a gap year but then I decided no, it's not an option. I'll just have to keep on praying and hope everything will be ok.

and

I failed all my subjects and then I had to decant [enter an extended degree programme]. Either decant or drop out. I said no, I'm not going to drop out, I have to keep on going.

These quotes highlight that she considers her options as she moves along in her studies and each time pushes herself to move forward despite depression and low selfesteem.

\section{New Zealand}

The New Zealand project gathered narratives from three different cohorts of students. Participants were invited to participate in a session utilising the Talanoa methodology (Vaioleti 2006); loosely translated into talking about nothing in particular (tala means to talk or tell and noa means nothing or of no value). The context created by Talanoa allows the students to feel a sense of connectedness as it is 'a personal encounter where people story their issues, their realities and aspirations... allows for a more mo'oni [pure, real, authentic conversation' (Vaioleti 2006, p1). 
The discussions focused on students' narratives of their journey into and their journey through the university, and how they see themselves as members of the academy. All the narratives were recorded and a thematic analysis of the data undertaken. As in the South African study, participatory learning and action methodologies (Bozalek, et al. 2010) were used, asking students to draw how they see themselves in their journeys into and through the university.

Seli is a law student who is of Samoan descent. Her drawing together with her narrative or Talanoa illustrates several themes in relation to student journeys in higher education.

Figure 3: Seli’s drawing

\section{SAMOAN CATHOLIC AcCouninto}
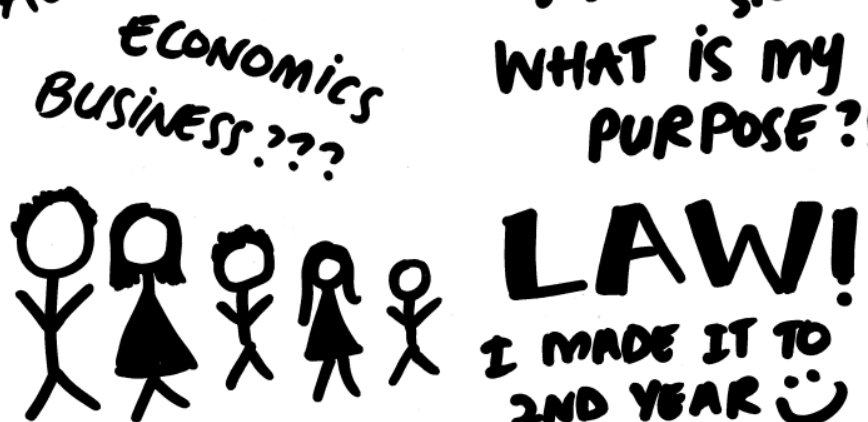
2MD VEAR $\ddot{Z}$
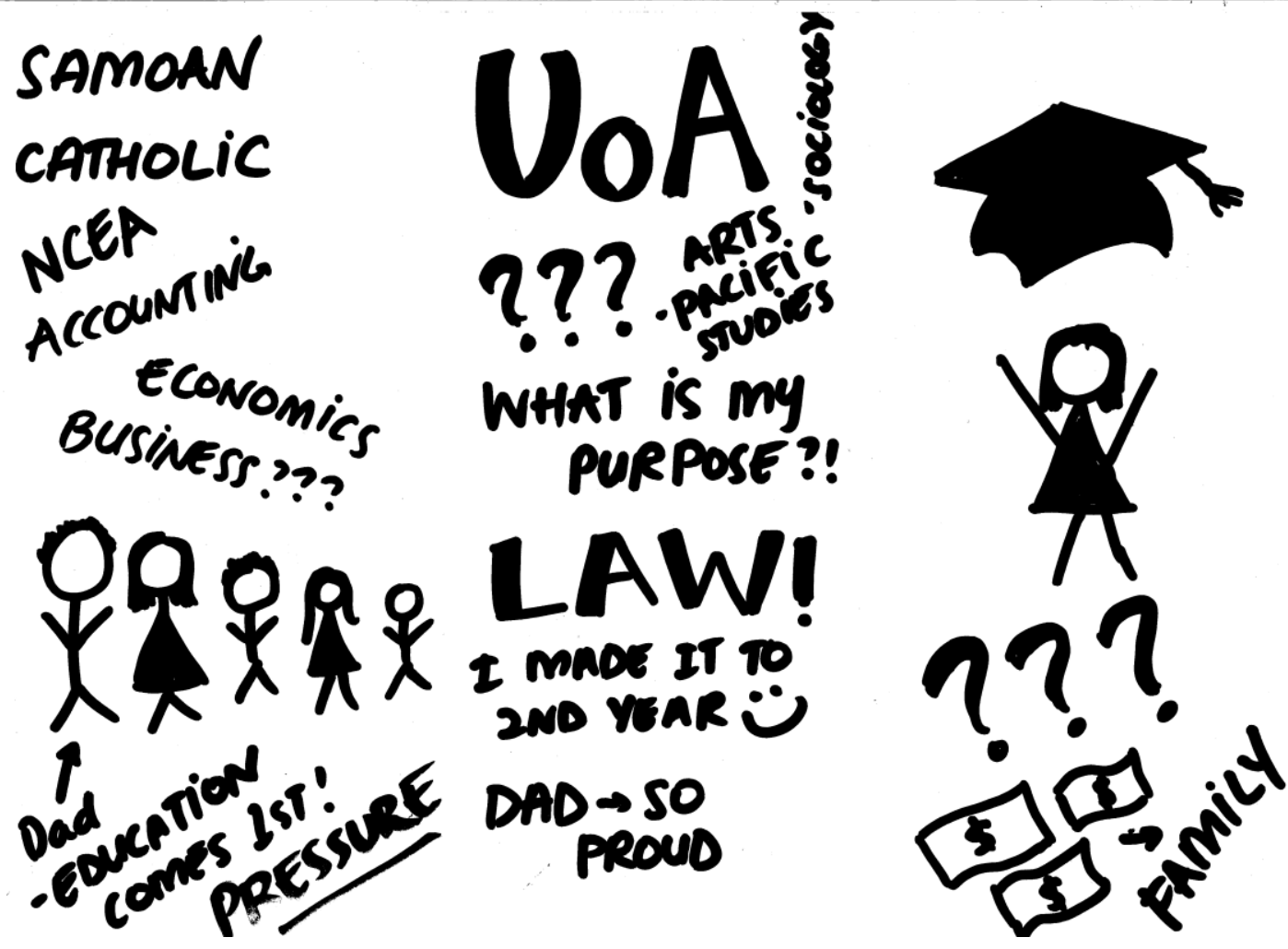

Seli's narrative details the importance of being first in her family to attend university, as she describes a journey not just for herself but for family (both immediate and extended) as well as for community members. There is a genuine desire for 'first in the family to university' students to give back to their family members and to others who have helped them along the way.

I am my parents' second born, my eldest brother did not finish high school. So it's up to me now to study and make sure I graduate. I am my father's hope. My parents support me, they work hard, give me money if I need it and help me to balance my studies and other responsibilities.

Seli's journey into university was not straightforward:

My advisor at school suggested that I apply to another university (one which requires a much lower entry score). When I told my dad he said no, that I should try this institution he heard on the news that 
it was ranked the highest in this country. I'm glad I applied here because I got accepted.

When Seli got into law school she felt that her family did not understand how difficult studying at higher education was, and sought support from her peers:

If it wasn't for my friends I wouldn't enjoy being at Law School. I don't have a friend who is not a Pacific Islander. How are we supposed to learn from one another? I mean...they say learn from other students but I find it difficult as I only have friends who are Pasifika. Sometimes other students look at us (Pacific Island) with the attitude that we only got here because of the target scheme...like... we're not smart enough to be here.

When reflecting on her experiences, she acknowledge the importance of making use of the student support services:

Don't be embarrassed to ask for help.....it's overwhelming at first but ask for help. Take your grades seriously and aim higher. Don't just aim to pass.

\section{The value of narrative}

The narrative fragments presented in this paper demonstrate that personal and academic development is a continuous and intertwined process influenced by a wide range of social, academic and personal factors. As such, students' sense of satisfaction with their experiences varied throughout their studies, whereas snapshot surveys may only give a partial view of students' experiences.

Students may engage differentially with their higher education experiences (Bryson, et al. 2012), with different influences taking priority over the period of a year (Wilcox, et al. 2005). The narratives of Jack, Maria and John demonstrated this as they struggled to develop as independent autonomous learners, raising questions about students' readiness for degree-level working and the impact it has on their engagement, achievement and satisfaction. Zandi's story highlights the varying experience that one student can have within such a short period of time, and how this is shaped by events and people, such as friends and mentors. The stories of Ntombi and Seli also reveal the influence of external pressures on student experiences.

The concept of the 'student life cycle' is common within higher education and is used to describe the annual cycle of the institutional processes from recruitment through to graduation. However, this is essentially an institutional view of students' experiences, appropriate for managers and academic teams but not for individual students. Students do not have a 'student life cycle'. For them, 'being a student' is part of a personal life journey, and their transitions and educational experiences are wide-ranging (Hamshire, et al. 2010, Hamshire, et al. 2012).

As students move forward in their studies from one stage to the next, their transitions are not only a change process but also a transfer to a new identity (Bangeni, et al. 2007, Ecclestone, et al. 2010). Previous research has indicated that if there is a 'match' between academic preparedness of an individual and the academic experience, the student is more likely to engage with the programme (Thomas 2002, Tinto, et al. 1993), and the more students are actively engaged the more likely they are to continue in higher education (Crosling, et al. 2008). Bryson and Hardy (Bryson, 
et al. 2012) made it clear that students' personal circumstances influence both their academic engagement and sense of 'being a student'. Individual expectations can have a profound impact upon students' perceptions of their learning experiences (Ecclestone, et al. 2010) and new students can need support in adapting to the culture of higher education (Wilcox, et al. 2005). Students may engage differentially with their higher education experiences (Bryson, et al. 2012), with various different factors taking priority within a year (Wilcox, et al. 2005).

Both the degree of adjustment from prior learning environments and the resemblance to previous learning experience can have an effect on achievement (Torenbeek, et al. 2010). Recording the stories of students from a range of groups, such as first generation students (worldwide) and Indigenous students (who are, for example, in Australia, New Zealand and South Africa, under-represented in higher education participation and achievement), can bring unfamiliar situations to the attention of university educators and managers. The narratives of non-traditional students provide a better understanding of the 'complexity of issues surrounding... access and retention' (O'Shea 2007, p. 15), and point to areas for further exploration.

\section{Limitations of Narrative}

There are practical limitations to narrative research: for instance, only those who choose to participate will share their stories; it requires a great deal of researcher time to gather and then analyse the data.

Narrative research cannot pretend to provide a full picture of the experiences of every student, any more than quantitative data collection can. Studies such as the ones used here illustrate the diversity of students' individual journeys, and remind those working in higher education of the pitfalls associated with considering students as a homogenous group.

However, a series of narratives of the journeys of a range of students can be used alongside quantitative snapshots from larger samples taken at a single point in time, to support institutional dialogue and enhancement in partnership with students. Findings could, subsequently, be fed into a personal tutorial system that uses open questions to encourage students to reflect on their experiences and to share their achievements and difficulties with university study, enabling tutors to make responsive changes to courses.

\section{Conclusions}

Central to the studies presented here was the aim of listening to students tell their stories in their own words, as they developed and transformed over time, so that everyday experiences could be contextualised by providing students with an opportunity for reflection.

It would not, of course, be practical to try to capture each student's journey through a course, but it would be appropriate to try to use narrative research judiciously to equip colleagues with a sense of the variety of individual experiences. Only the users of a service can truly give an insight into its on-going impact on their experiences. Many educators are very experienced at capturing and analysing student perceptions from their classroom interactions, and at responding to them at an individual level, but 
a more systematic approach to listening to the personal stories of students could be used effectively to support enhancement.

A selection of students' stories could be collected when there have been changes to the curriculum or infrastructure, or to the characteristics of the student population. Students could be encouraged to collect such narratives from each other.

Performance indicators are only part of what is needed to gain an insight into students' experiences; there is no single tool that can be used to 'measure' experience. Quantitative evidence is better used with qualitative corroboration to enrich understanding of students' experiences, to initiate dialogues about enhancement and to inform policy and procedure. Narratives provide a counterpoint to student survey responses and provider richer and more evocative data. 


\section{References}

Andrew, N., McGuinness, C., Reid, G. and Corcoran, T., 2009, 'Greater than the sum of its parts: Transition into the first year of undergraduate nursing', Nurse Education in Practice, 9(1), pp. 13-21.

Bangeni, B. and Kapp, R., 2007, 'Shifting language attitudes in linguistically diverse learning environment in South Africa', Journal of Multilingual and Multicultural Development, 28(4), pp. 253-269.

Barnett, R., 1994, The limits of competence: knowledge, higher education and society, (Buckingham, OUP/SRHE).

Barnett, R., 2007, A will to learn, (Maidenhead, OUP/McGraw-Hill International).

Bennett, R. and Kane, S., 2014, 'Students' interpretations of the meanings of questionnaire items in the National Student Survey', Quality in Higher Education, 20(2), pp. 129-164.

Benseman, J., Coxon, E., Anderson, H. and Anae, M., 2006, 'Retaining nontraditional students: lessons learnt from Pasifika students in New Zealand', Higher Education Research \& Development, 25(2), pp. 147-62.

Bishop, R., 2003, 'Changing Power Relations in Education: Kaupapa Maori messages for'mainstream'education in Aotearoa/New Zealand', Comparative Education, 39(2), pp. 221-38.

Bozalek, V. and Biersteker, L., 2010, 'Exploring power and privilege using participatory learning and action techniques', Social Work Education, 29(5), pp. 551-72.

Braun, V. and Clarke, V., 2006, 'Using thematic analysis in psychology', Qualitative research in psychology, 3(2), pp. 77-101.

Brennan, J. and Williams, R., 2004, Collecting and using student feedback, (York, Learning and Teaching support network (LTSN).)

Britton, C. and Baxter, A., 1999, 'Becoming a Mature Student: Gendered narratives of the self', Gender and Education, 11(2), pp. 179-93.

Bryson, C. and Hardy, C., 2012, 'The nature of academic engagement: what the students tell us', in Solomonides, I., Reid, A. and Petocz, P. (Eds) Engaging with learning in higher education (Faringdon, Libri Publishing).

Buckley, A., 2012, Making it count: Reflecting on the National Student Survey in the process of enhancement, (York, Higher Education Academy).

Case, J. M., Marshall, D. and Linder, C. J., 2010, 'Being a student again: A narrative study of a teacher's experience', Teaching in Higher Education, 15(4), pp. 423-33.

Chilisa, B., 2011, Indigenous research methodologies, Sage Publications).

Chu, C., Abella, I. S. and Paurini, S., 2013, Educational practices that benefit Pacific learners in tertiary education, (Wellington, Ako Aotearoa, National Centre for Tertiary Teaching Excellence).

Coates, H., 2010, 'Defining and monitoring academic standards in Australian higher education', Higher Education Management and Policy, 22(1), pp. 1-17.

Council on Higher Education, 2016, 2013 Higher Education Data: Participation, (Brummeria, Council on Higher Education).

Crosling, G., Thomas, L. and Heagney, M., 2008, Improving Student Retention in Higher Education, (Abingdon, Routledge).

Devlin, M. and O'Shea, H., 2012, 'Effective university teaching: Views of Australian university students from low socio-economic status backgrounds', Teaching in Higher Education, 17(4), pp. 385-97. 
Ecclestone, K., Field, J., Gallacher, J. and Ingram, R., 2010, 'Lost and found in transition', Researching transitions in lifelong learning, pp. 1-27.

Elliott, J., 2007, Using narrative in social research: Qualitative and quantitative approaches, (London, Sage).

Gibbs, G., 2012, Implications of 'Dimensions of quality' in a market environment, (York, Higher Education Academy).

GraduateCareers Australia, 2016, Australian Graduate Survey, GraduateCareers Australia)

Gubrium, J. F. and Holstein, J. A., 2009, Analyzing Narrative Reality, (London, Sage).

Hamshire, C. and Cullen, R., 2010, 'Developing a spiralling induction programme: a blended approach', in Anagnostopoulou, K. and Parmar, D. (Eds) Supporting the First Year Student Experience through the Use of Learning Technologies (York, Higher Education Academy).

Hamshire, C. and Wibberley, C., 2014, 'The listening project: Physiotherapy students narratives of their higher education experiences', in Bryson, C. (Eds) Understanding and developing student engagement (Abingdon, Routledge).

Hamshire, C., Willgoss, T. G. and Wibberley, C., 2012, 'What are reasonable expectations? Healthcare student perceptions of their programmes in the North West of England', Nurse Education Today, 33(2), pp. 173-9.

Hazelkorn, E., 2007, 'The impact of league tables and ranking systems on higher education decision making', Higher education management and policy, 19(2), pp. 1-24.

Higher Education Statistics Agency (HESA), 2016, Widening Participation of Underrepresented Groups, (Cheltenham, Higher Education Statistics Agency).

Kapp, R. and Bangeni, B., 2011, 'A longitudinal study of students' negotiation of language, literacy and identity', Southern African Linguistics and Applied Language Studies, 29(2), pp. 197-208.

Koch, T., 1998, 'Story telling: is it really research?', Journal of Advanced Nursing, 28(6), pp. 1182-90.

Law, D. C. S., 2010, 'Quality assurance in post-secondary education: the student experience', Quality Assurance in Education, 18(4), pp. 250-70.

Lieblich, A., Tuval-Mashiach, R. and Zilber, T., 1998, Narrative research: Reading, analysis, and interpretation, (London, Sage).

Molesworth, M., Nixon, E. and Scullion, R., 2009, 'Having, being and higher education: the marketisation of the university and the transformation of the student into consumer', Teaching in Higher Education, 14(3), pp. 277-87.

Nomdo, G., 2006, 'Identity, power and discourse: The socio-political selfrepresentations of successful 'black' students', in Thesen, L. and van Pletzen, E. (Eds) Academic literacy and the languages of change

O'Shea, S. E., 2007, 'Well I got here... but what happens next? Exploring the early narratives of first year female students who are the first in the family to attend university', Journal of Australian and New Zealand Student Services Association, 29(April 2007), pp. 36-51.

Palmer, M., O'Kane, P. and Owens, M., 2009, 'Betwixt spaces: student accounts of turning point experiences in the first-year transition', Studies in Higher Education, 34(1), pp. 37-54.

Ramsden, P., Batchelor, D., Peacock, A., Temple, P. and Watson, D., 2010, Enhancing and Developing the National Student Survey, (London, Institute of Education).

Riessman, C. K., 2008, Narrative methods for the human sciences, (London, Sage). 
Solomonides, I., Reid, A. and Petocz, P., 2012, 'A Relational model of student engagement', in Solomonides, I., Reid, A. and Petocz, P. (Eds) Engaging with learning in higher education (Faringdon, Libri Publishing).

South African Survey of Student Engagement (SASSE), 2012, South African Survey of Student Engagement, (Bloemfontein, University of the Free State ). Available at http://sasse.ufs.ac.za/ (accessed 16/10/2016).

Squire, C., 2008, 'Experience-centred and culturally-oriented approaches to narrative', in Andrews, M., Squire, C. and Tamboukou, M. (Eds) Doing Narrative Research (London, Sage).

The World Bank, 2016, Gross enrolment ratio, tertiary, both sexes, (Washington, The World Bank). Available at http://data.worldbank.org/indicator/SE.TER.ENRR (accessed 16/10/2016).

Thomas, L., 2002, 'Student retention in higher education: the role of institutional habitus', Journal of Education Policy, 17(4), pp. 423-42.

Tinto, V. and Goodsell, A., 1993, A Longitudinal Study of Freshman Interest Groups at the University of Washington, (Washington, DC, Office of Educational Research and Improvement).

Torenbeek, M., Jansen, E. and Hofman, A., 2010, 'The effect of the fit between secondary and university education on first-year student achievement', Studies in Higher Education, 35(6), pp. 659-75.

Urwin, S., Stanley, R., Jones, M., Gallagher, A., Wainwright, P. and Perkins, A., 2010, 'Understanding student nurse attrition: learning from the literature', Nurse Education Today, 30(2), pp. 202-07.

Vaioleti, T. M., 2006, 'Talanoa research methodology: A developing position on Pacific research', Waikato Journal of Education, 12(2006), pp. 21-34.

Webster, L. and Mertova, P., 2007, Using narrative inquiry as a research method: An introduction to using critical event narrative analysis in research on learning and teaching, (London, Routledge).

Wilcox, P., Winn, S. and Fyvie-Gauld, M., 2005, "It was nothing to do with the university, it was just the people": the role of social support in the first-year experience of higher education', Studies in Higher Education, 30(6), pp. 70722.

\section{List of figures}

Figure 1: Zandi's journey

Figure 2: Ntombi's drawing of a two-sided face

Figure 3: Seli’s drawing 